\title{
The Concept of a Research Reactor of Small Power for Isotope Processing
}

\section{Yu. E. Karazhielievskaia, Y. V. Levchenko, A. S. Zevyakin, A. M. Terekhova, D. G. Lazarenko, and G. E. Lazarenko}

National Research Nuclear University MEPhI (Moscow Engineering Physics Institute), Kashirskoe shosse 31, Moscow, 115409, Russia

\section{Abstract}

The concept of a low-power research reactor for the production of radioisotopes is proposed, the results of calculations of the neutron-physical parameters of the core are presented, which can be used to substantiate the claimed reactor characteristics. In this article, the characteristics of the core of a research reactor of low power is substantiated, the main purpose of which is the production of radioisotope products for medical purposes. Nuclear medicine is one of the most advanced and demanded

Corresponding Author: Yu. E. Karazhielievskaia YEKaraxhelevskaya@mephi.ru

Received: 22 July 2018 Accepted: 9 September 2018 Published: 8 October 2018

Publishing services provided by Knowledge $\mathrm{E}$

(c) Yu. E. Karazhielievskaia et al. This article is distributed under the terms of the Commons Attribution License, which permits unrestricted use and redistribution provided that the original author and source are credited.

Selection and Peer-review under the responsibility of the Breakthrough Directions of Scientific Research at MEPhl Conference Committee.

\section{G OPEN ACCESS} in the world of modern high-tech medicine, based on the using of atomic nucleus properties. As a rule, atoms with unstable nuclei are radionuclides. The reactor method of radionuclide production allows obtaining large quantities of radioisotope products at a relatively low price, but the reactor base is currently rather limited.

Keywords: radioisotope products, research reactors, neutron-physical characteristics

\section{Introduction}

In connection with rapidly developing technologies, there is a problem of operating radionuclides of medical purpose. The surge of medical interest in isotopes is explained by the high effectiveness of their application in diagnostics. It is for diagnostic purposes that today about $98 \%$ of isotopes entering the medical sector are used. The uniqueness of isotope diagnostics lies in its accuracy, reliability, the possibility of frequent use, and most importantly, the ability to diagnose the disease at an early stage. Radionuclides and their compounds are widely used for conducting diagnostic studies in cardiology, oncology, endocrinology, pulmonology, urology, neurology and other fields of medicine. The most significant are the isotopes ${ }^{90} \mathrm{Y},{ }^{88} \mathrm{Re},{ }^{99 m} \mathrm{TC},{ }^{99} \mathrm{Mo},{ }^{68} \mathrm{Ga},{ }^{123} \mathrm{I},{ }^{131} \mathrm{I}$ and others [4].

Promotion of Russian nuclear technologies to world markets is one of the priority activities of SAEC Rosatom. To date, agreements have been reached on the establishment of scientific nuclear centers in Vietnam, Bolivia, Nigeria, etc. The list of tasks to be 
solved by the centers includes research on the use of nuclear technology for medical purposes. At the same time, to date, there are no nuclear reactors designed specifically for these purposes. The development of radiopharmaceuticals is carried out at the reequipped facilities, in connection with which, optimal operating modes are not always achieved, which leads to a decrease in efficiency and a significant increase in the cost of the products.

\section{Materials and Methods}

The research reactor was designed according to the scheme of a water-cooled reactor with a natural circulation of the coolant. Its distinctive feature is the low temperature of the coolant (below $90^{\circ} \mathrm{C}$ ), which avoids loading the reactor vessel with internal pressure. This will ensure continued safe operation of the reactor. The prototype was the design of serial reactors of the type VVR and IRT [1]. The thermal power of the reactor is up to $10 \mathrm{MW}$. The size of the reactor tank is selected from the condition of a low level of activation of its material at the end of the campaign, permitting general industrial processing without burial. The height of the column of the coolant (water) above the core is determined by the requirements of radiation safety.

The core of the reactor core is the shortened fuel assemblies of the VVER-440 reactor [2], which allows organizing their production on existing equipment. The active zone contains 85 truncated fuel assemblies, around the core is a beryllium reflector $17 \mathrm{~cm}$ thick (Figure 1). The height of the core is $156 \mathrm{~cm}$, diameter is $146 \mathrm{~cm}$. Each fuel cassette contains 120 fuel elements. More detailed characteristics of the core are presented in Table 1.

In the active zone of the reactor, it is planned to make several vertical channels for targets in which isotopes for medical purposes will be produced, such as ${ }^{90} \mathrm{Y}$, ${ }^{88} \mathrm{Re}$, ${ }^{99 m} \mathrm{Tc},{ }^{99} \mathrm{Mo},{ }^{68} \mathrm{Ga},{ }^{123} \mathrm{l},{ }^{131} \mathrm{I}$ and others.

Neutron-physical calculations were carried out on the Serpent software complex, developed at the State Scientific and Technical Center in Finland in 2004.

PC Serpent is a software complex that implements the Monte Carlo method and allows calculations using the detailed dependence of neutron cross-sections on energy and the maximum possible detail of the model. The following calculations are possible:

1. changes in the nuclide composition of nuclear fuel during irradiation in the reactor;

2. the effective coefficient of neutron multiplication (Keff) of arbitrarily complex systems, using for their description three-dimensional geometry; 


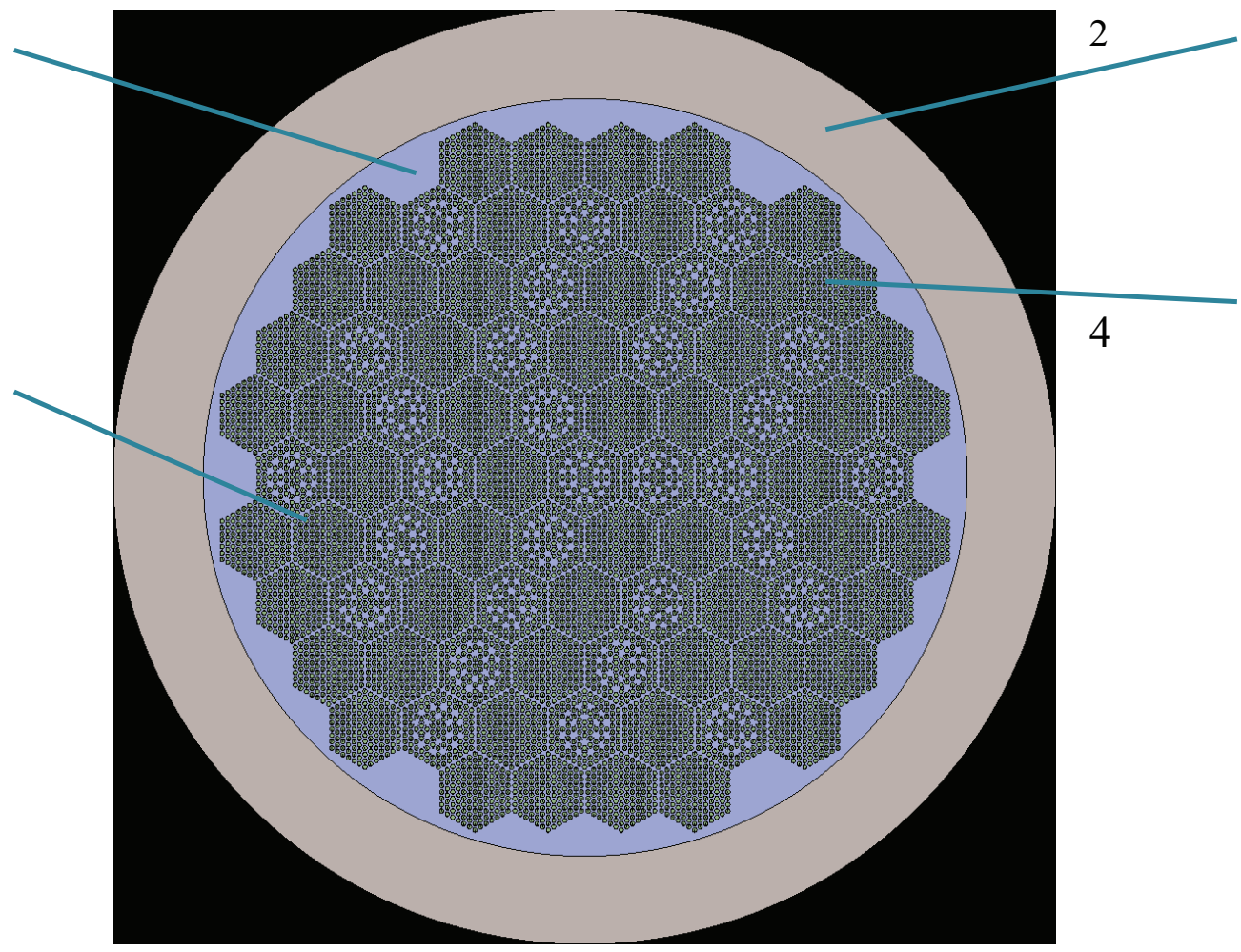

Figure 1: Cartogram of the core of the research reactor: 1 - Moderator; 2 - beryllium reflector; 3 - fuel assembly guide channels; 4 - fuel assembly.

TABLE 1: Main characteristics of the reactor core of a research reactor.

Characteristics, measurement unit
Power of the reactor
Coolant
Moderator
Reflector
Reactor core height, cm
Reactor core diameter, cm
Number of fuel assembly, items fuel assembly with
the technological channels of the control rods, items
fuel assembly without the technological channels of
the control rods, items
Number of the technological channels in the control
rods, items
Fuel assembly lattice spacing, cm
Fuel pin lattice spacing, cm
Number of fuel pins in the fuel assembly, items
The gas gap width, cm
Fuel pellet diameter, cm

\begin{tabular}{|c|}
\hline Value \\
\hline $10 \mathrm{MW}$ \\
\hline Water \\
\hline Water \\
\hline Beryllium \\
\hline 156 \\
\hline 146 \\
\hline 85 \\
\hline 30 \\
\hline 55 \\
\hline 18 \\
\hline 14 \\
\hline 1.22 \\
\hline 127 \\
\hline 0.16 \\
\hline 0.756 \\
\hline
\end{tabular}

3. distribution of energy release through the zones of the reactor installation;

4. activities of spent nuclear fuel; 
5. temperature effects of reactivity; and

6. rates of various reactions [3].

Serpent uses two- or three-dimensional geometry to create computational models, which allows simulating the loading of a whole reactor with the ability to describe each individual element, channel or cell of the core.

The Serpent software package allows to specify cylindrical and spherical fuel rods, square and hexagonal lattices of light water reactors and circular clusters for RBMK and CANDU reactors [5].

The calculation of the effective neutron multiplication factor using Serpent is based on the simulation of real neutron-physical processes occurring in the reactor using a statistical approach.

\section{Results}

Neutron-physical calculations of the core of the research reactor were carried out for two different fuel compositions. In the first case, a U-Th metal fuel compound is used. The share of uranium in the mixture is $15 \%$, uranium enrichment by isotope ${ }^{235} \mathrm{U}$ is $11.8 \%$. In the second case, oxide fuel $(\mathrm{Th}+\mathrm{U}) \mathrm{O}_{2}$ is used with a fraction of uranium in the mixture of $15 \%$, uranium enrichment in ${ }^{235} \mathrm{U}$ is $19.5 \%$. The enrichment of uranium was selected from the working conditions of the fact that the reactor without overloading has been running for 10 years and the minimum value of the reactivity reserve at the end of the campaign remains. One of the conditions for limiting fuel enrichment was IAEA recommendations for uranium enrichment below $20 \%$ [6].

The effective coefficient of neutron multiplication at the beginning of the campaign in the first case is 1.0433, in the second 1.037. The statistical error of calculations on the Serpent PC was $0.05 \%$. The campaign lasts 10 years without overload. The fuel burnup at the end of the campaign is $5.11 \mathrm{MW}$ day/ $\mathrm{kg}$.

Figure 2 shows the results of a comparison of the effective neutron multiplication factor during the reactor campaign for the first and second fuel composition. As can be seen from the figure, the reactivity margin for metallic fuel is 3\%, and for oxide $4 \%$.

From the point of view of neutron-physical properties, metallic uranium is the best type of fuel, but the main disadvantages of using metal fuel in VVER-type reactors is the low operating temperature of the fuel. He is a very unstable material, because is prone to form change under the influence of high temperatures. The maximum 


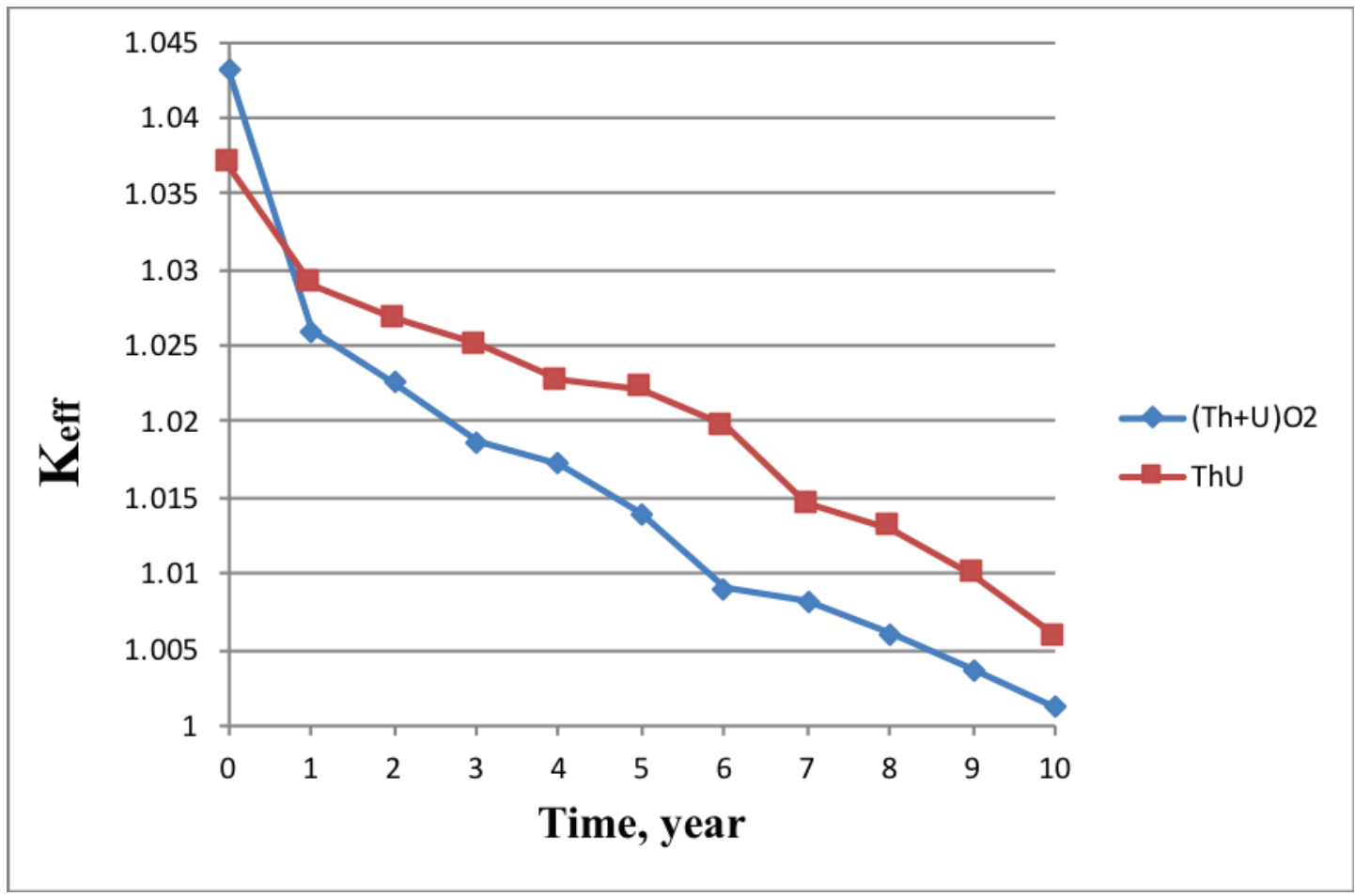

Figure 2: Dependence of the effective multiplication factor of the core of the research reactor on the nuclear fuel campaign for $\mathrm{UO}_{2}-\mathrm{ThO}_{2}$ and U-T fuel compositions.

temperature at which it can still work without significant shaping and swelling is 400 ${ }^{\circ} \mathrm{C}$ [7]. In the proposed work, the working temperature of the fuel is $260^{\circ} \mathrm{C}$.

\section{Conclusion}

The simple device of the reactor, the absence of circulating pumps, the bearing of the housing, the use of a cheap coolant (water), the small number of activated structural materials, the relative compactness of the plant as a whole, and the use of common industrial enrichment fuel make the research reactor concept attractive not only from the technical, points of view. At the same time, the export potential is provided by using fuel with enrichment below $20 \%$, which is in line with IAEA recommendations on the non-proliferation regime [6]. The design of the core, the channels under the target for the production of isotopes and the necessary neutron flux will allow to maintain isotopes for medical purposes, such as ${ }^{90} \mathrm{Y},{ }^{88} \mathrm{Re},{ }^{99 m} \mathrm{Tc},{ }^{99} \mathrm{Mo},{ }^{68} \mathrm{Ga},{ }^{123} \mathrm{I},{ }^{131} \mathrm{I}$ and others. 


\section{Funding}

The research was carried out within the framework of the subsidy for financial support for the execution of the state task for the performance of public services. Theme No. 00-g-995-2203.

\section{References}

[1] Bat, G., Kochenov, A., and Kabanov, L. (1985). Research Nuclear Reactors, p. 280. M.: Energoatomizdat.

[2] Budov, V. and Farafonov, V. (1985). Designing the Main Equipment of Nuclear Power Plants, p. 320. M.: Energoatomizdat.

[3] Leppanen, J. (2015). SERPENT - A Continuous Energy Monte-Carlo Reactor Physics Burnup Calculation Code. Helsinki: VTT Technical Research Centre of Finland.

[4] Fomin, R., Kolesov, V., and Kochnov, O. (June 21-23, 2016). Modeling of the core of the VVR-c reactor to increase the production of radioactive nuclides. Atomic power plants of extremely low power for applied and educational purposes, Obninsk.

[5] Karazhielievskaia, Yu., Terekhova, A., Stepanova, Yu., et al. (2015). Comparison of nuclear fuel burnup calculations for a test benchmark cell using the "SERPENT" and "MCNP-VISUALBURNOUT" software complexes. VI International Youth Scientific and Technical Conference "Electric Power as seen by Youth 2015". Ivanovo, ISEU.

[6] IAEA Safety Standards No. NS-R-4. (2010).

[7] Volkov, Yu. (1996). Physical and Technical Fundamentals of Designing Nuclear Reactors: Textbook. Obninsk, IATE. 